Journal of Engineering Science and Technology Review 7 (5) (2014) 62-65

Special Issue on Simulation of Manufacturing Technologies
JOURNAL OF

Engineering Science and

Technology Review

\title{
Computer Modeling in the Design of the Blade Blank for Linear Friction Welding
}

\author{
V. Bychkov*, A. Medvedev, E.Tarasenko, A. Pautov and M.Savitchev
}

Ufa State Aviation Technical University, Ufa, Russian Federation

Received 15 September 2014; Accepted 22 September 2014

\begin{abstract}
Welding of next nearest blades can be used to reduce the deformation of blade's profile during linear friction welding. Then the overlaps should be removed before welding the rest of the blades. To optimize the overlap's shape and minimise blade deviation from specifications, computer modeling should be used.
\end{abstract}

Keywords: Linear friction welding, Blisk, Blades, Deformations

\section{Introduction}

Blisk manufacturing using linear friction welding (LFW) requires the application of forces from tens to hundreds of $\mathrm{kN}$ to produce the necessary oscillatory movement without axially deforming blades $[1,2]$. To transfer these forces to the rubbing surface of the welded blanks, the blade's design should accommodate the larger force required to clamping blanks in the machine than that required for movement.

The shape and dimensions of the required parts overlap for LFW are limited by the inter-blade distance, material strength of the blade and tooling, and the tolerance that the airfoil profile can deviate from the designed position. The clamping forces of the blade and forging force distort this overlap of the blade and following LFW residual stresses arise in the blade [3-5] as well as permanent deformations of the blade.

During the design stage of the aluminum blade, the effect of the overlap's shape on the deviation of the blade profile from the specified position was studied. Computer modeling was performed for two cases of joining blades blanks to the disk of an aircraft engine compressor, which are shown in figure1

The second method used for LFW joining of blades is in the next to nearest manner and removing the overlap before welding the rest of blades. These two modes of overlap on a blade blank of aluminum alloy D16T were studied in modeling in DEFORM-3D by iterations to minimize the allowable square supporting surface of overlap provided that stress do not exceed yield strength of the material of blades.
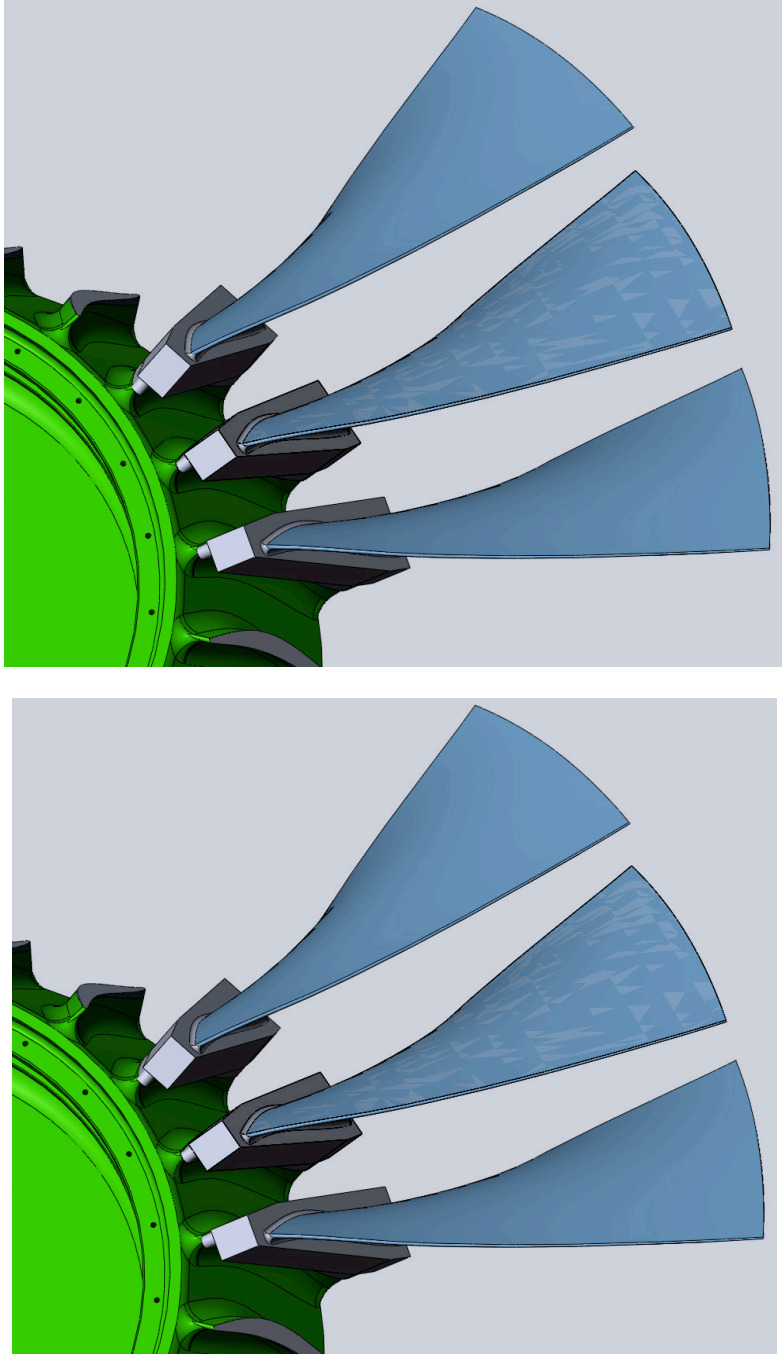

Fig. 1. Joining blade blanks to disks: sequential blades welding (top) and next nearest blade welding (bottom).
*E-mail address: otsp-ugatu@mail.ru

ISSN: 1791-2377 (C) 2014 Kavala Institute of Technology. All rights reserved. 


\section{Model}

The figure 2 shows possible arrangements for clamping the blade blanks in the LFW equipment along with clamping force $\mathrm{P} 3$ and friction force $\mathrm{P} 0$.

In modeling the friction force was applied as uniform pressure to the top of the overlap and to the top of the welding interface. For designing the welding tooling it was assumed that tolling consisted of perfectly rigid bodies with all points on the supporting surfaces of the tooling being fixed in this direction to prevent movement of the blade blank under the action of forces.

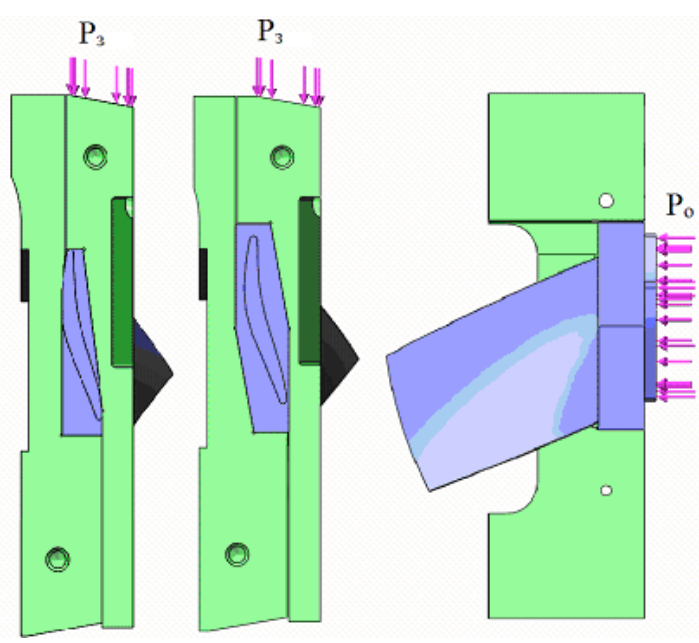

Fig.2. Application of forces to the blade blank

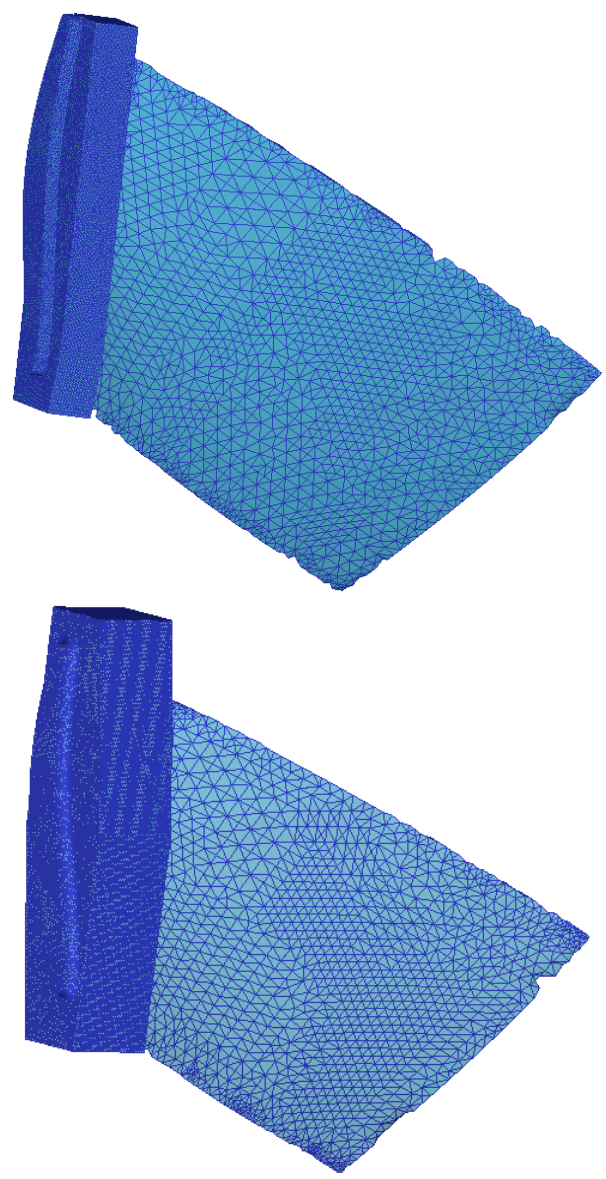

Fig.3. Mesh of 3D models of blade blanks.
Figure 3 shows 3D models of blades blanks for two cases of overlap.

In modeling the deflected mode of blade blanks the clamping force was set to $100 \mathrm{kN}$, friction force at $99.5 \mathrm{kN}$ and oscillatory force at $99.5 \mathrm{kN}$. The clamping force was applied to the inclined surface of the overlap in the direction of oscillation, which works as a wedge and holds the blade blank. The minimum mesh size was set to $1.5 \mathrm{~mm}$.

During the LFW process maximum stresses and strains develop in the blank blade when the oscillatory force is in the same direction as the clamping force. So this worst case was taken for modelling.

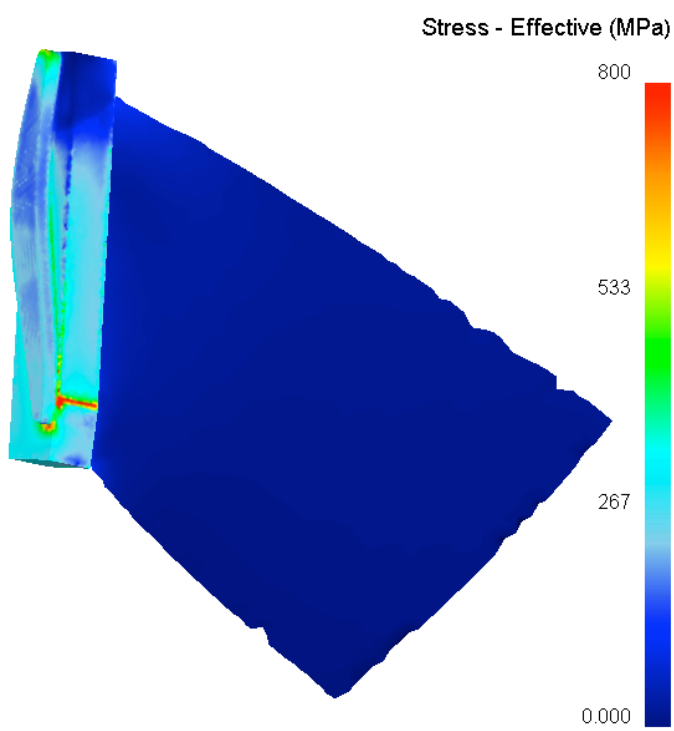

(a)

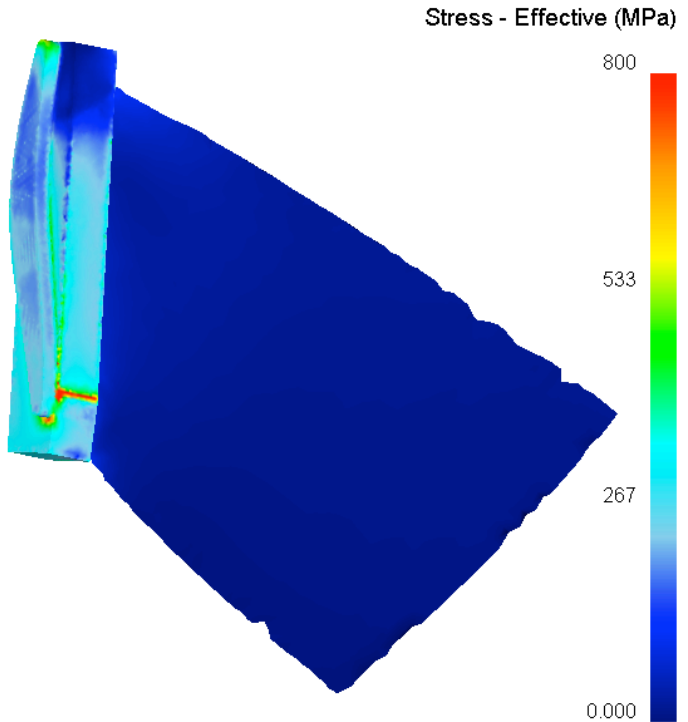

(b)

Fig.4. Effective stresses for the welding case 1 (top) and for the welding case 2 (bottom) 
V. Bychkov, A. Medvedev, E.Tarasenko, A. Pautov and M.Savitchev /

Journal of Engineering Science and Technology Review 7 (5) (2014) $62-65$

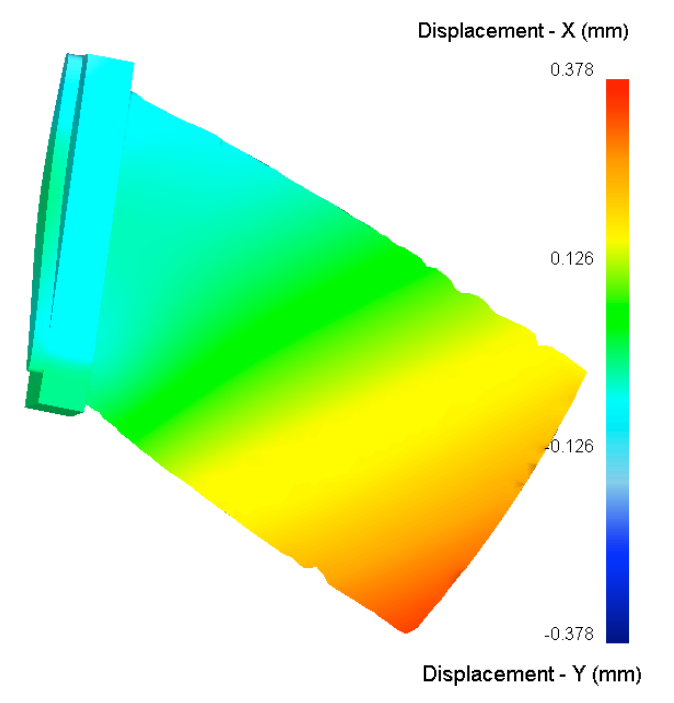

(a)

X-Axis
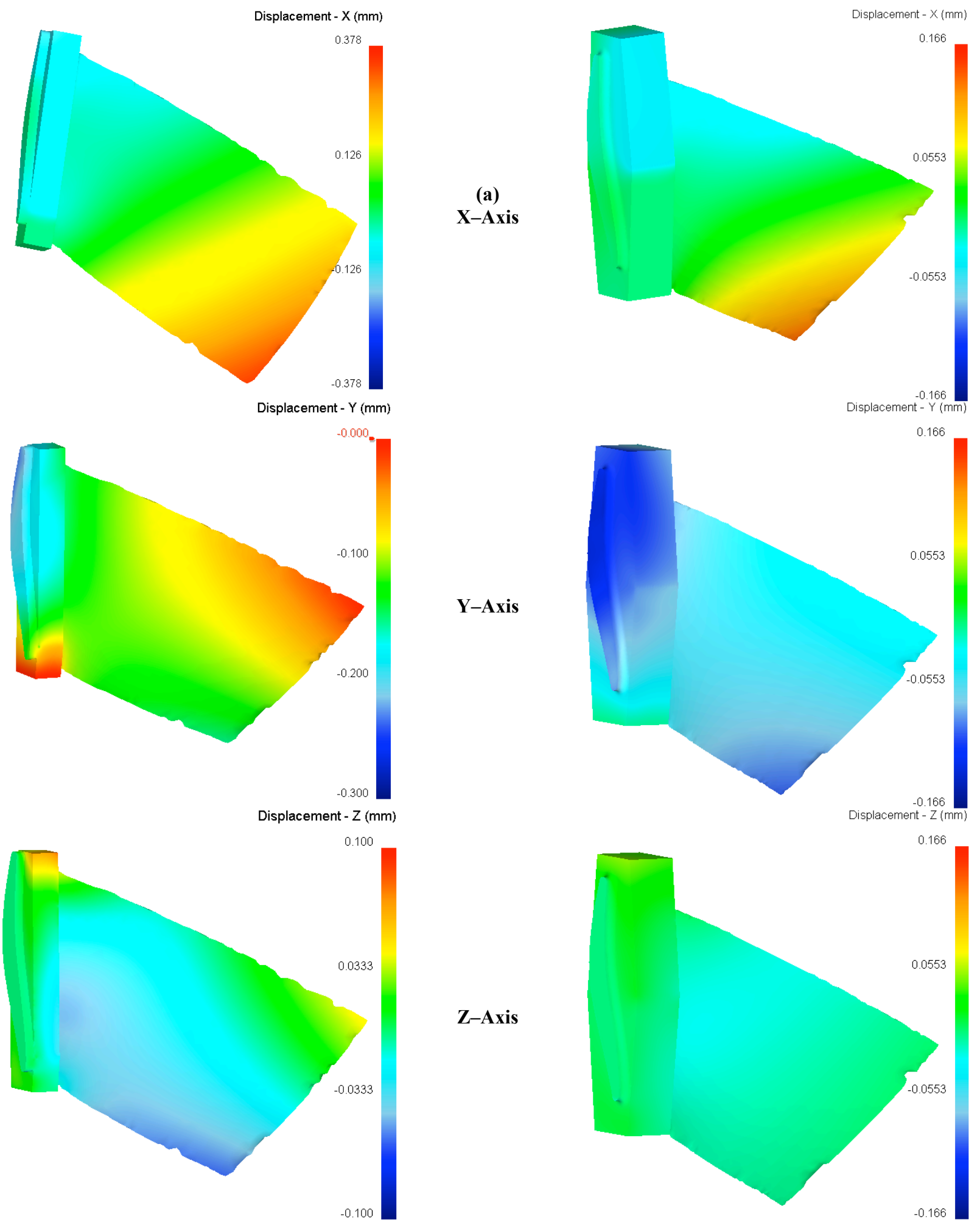

Fig.5. Effective displacements along axes X (top), Y (middle) and Z (bottom) for different welding cases: the case 1 (left), the case 2 (right).

\section{Results and discussions}

The stress field calculated in modeling of the first case of welding are shown in Figure 4 (a). Stresses in the blade blank are less than yield stress except in one edge, where edge deformation is possible. The maximum of displacement appears at the end of the blade along the direction of blisk rotation $-0,4 \mathrm{~mm}$ (Figure 5, top at left column). Displacements along the other directions at the end of the blade are much smaller and do not exceed $0.2 \mathrm{~mm}$ along the direction of oscillation and $0.1 \mathrm{~mm}$ along the direction of friction force (Figure 5, middle and bottom at left column). 
For the second case of welding, as shown in Figure 1, modeling results of stresses in the blade blank shown in Figure 4 (b). Stresses in the blank are less than the yield stress of the material. The maximum displacement occurs at the end of the blade along the direction of blisk rotation $0.13 \mathrm{~mm}$ (Figure 5, top at right column). Displacements at the end of the blade along other directions are much smaller and do not exceed $0.1 \mathrm{~mm}$ (Figure 5, middle and bottom at right column)

\section{Conclusions}

In this paper the basic processing involved in the receiver of the OFDM system is described and simulated. Matlab simulation results for the $2 \mathrm{k}$ mode of the DVB-T standard are obtained and presented. Simulation results correspond to the theoretical ones.

The next objective of this work is to simulate Bit Error Rate (BER) and Peak to Average Power Ratio (PAPR) for FFT based OFDM system, as well as, to study and simulate of OFDM performance over a multipath channel

\section{Acknowledgments}

This work was produced during the joint project between USATU (Ufa State Aviation Technical University) and UMPO (Ufa Engine Industrial Association) with title "Elaboration and industrial development of high-precision shaping coordinated technologies and superficial hardening of responsible details from Al-alloys with heightened constructional energy efficiency", implemented under the contract №40/10-30976 sponsored by the Ministry of Education and Science of the Russian Federation (contract №02.G25.31.0010 between UMPO and the Ministry of Education and Science of the Russian Federation) through the Resolution of the Russian Federation Government № 218 from April 9, 2010.

\section{References}

[1] A. Medvedev, A. Vairis, R. Nikiforov and A. Supov. Energy Balance of the Linear Friction Welding Process. Journal of Engineering Science and Technology Review Volume 5, Issue 3, 2012, pages 20-24.

[2] A. Medvedev, V. Bychkov, A. Selivanov, S Pavlinich, S. Dautov, A Soupov / Application of the linear friction welding for joining alloys VT6 and VT8-1 . Herald USATU - 2012 T. 16, № 7 (52). S. 63-67. (In Russian)

[3] A. Medvedev, V. Bychkov, E. Tarasenko, N. Izmailova, A. Dubin / Investigation of residual stresses in the joints obtained by linear friction welding. Herald USATU - 2012 T. 16, № 7 (52). S. 59-62. (In Russian)

[4] Vairis, A., Frost, M., "Design and commissioning of a friction welding machine", Journal of Materials and Manufacturing Processes, 2006, vol.21, no.8, pp. 766-773.

[5] Vairis, A., Petousis, M., "Designing experiments to study welding processes: using the Taguchi method", Journal of Engineering Science and Technology Review, 2009, vol.2, no.1, pp.99-103. 